\title{
Association between heat stress and oxidative stress in poultry; mitochondrial dysfunction and dietary interventions with phytochemicals
}

Abdollah Akbarian ${ }^{1,2+}$, Joris Michiels ${ }^{3 * \dagger}$, Jeroen Degroote ${ }^{3}$, Maryam Majdeddin ${ }^{1,2,3}$, Abolghasem Golian $^{2}$ and Stefaan De Smet ${ }^{1}$

\begin{abstract}
Heat as a stressor of poultry has been studied extensively for many decades; it affects poultry production on a worldwide basis and has significant impact on well-being and production. More recently, the involvement of heat stress in inducing oxidative stress has received much interest. Oxidative stress is defined as the presence of reactive species in excess of the available antioxidant capacity of animal cells. Reactive species can modify several biologically cellular macromolecules and can interfere with cell signaling pathways. Furthermore, during the last decade, there has been an ever-increasing interest in the use of a wide array of natural feed-delivered phytochemicals that have potential antioxidant properties for poultry. In light of this, the current review aims to (1) summarize the mechanisms through which heat stress triggers excessive superoxide radical production in the mitochondrion and progresses into oxidative stress, (2) illustrate that this pathophysiology is dependent on the intensity and duration of heat stress, (3) present different nutritional strategies for mitigation of mitochondrial dysfunction, with particular focus on antioxidant phytochemicals.

Oxidative stress that occurs with heat exposure can be manifest in all parts of the body; however, mitochondrial dysfunction underlies oxidative stress. In the initial phase of acute heat stress, mitochondrial substrate oxidation and electron transport chain activity are increased resulting in excessive superoxide production. During the later stage of acute heat stress, down-regulation of avian uncoupling protein worsens the oxidative stress situation causing mitochondrial dysfunction and tissue damage. Typically, antioxidant enzyme activities are upregulated. Chronic heat stress, however, leads to downsizing of mitochondrial metabolic oxidative capacity, up-regulation of avian uncoupling protein, a clear alteration in the pattern of antioxidant enzyme activities, and depletion of antioxidant reserves. Some phytochemicals, such as various types of flavonoids and related compounds, were shown to be beneficial in chronic heat-stressed poultry, but were less or not effective in non-heat-stressed counterparts. This supports the contention that antioxidant phytochemicals have potential under challenging conditions. Though substantial progress has been made in our understanding of the association between heat stress and oxidative stress, the means by which phytochemicals can alleviate oxidative stress have been sparsely explored.
\end{abstract}

Key words: Antioxidant enzymes, Avian uncoupling protein, Electron transport chain, Flavonoids, Heat Stress, Mitochondrion, Oxidative stress, Poultry

\footnotetext{
* Correspondence: joris.michiels@ugent.be

${ }^{\dagger}$ Equal contributors

${ }^{3}$ Department of Applied Biosciences, Ghent University, Valentin Vaerwyckweg

1, Ghent 9000, Belgium

Full list of author information is available at the end of the article
} 


\section{Background}

Heat exposure affects poultry production on a worldwide basis and has a significant impact on well-being and production. Heat stress (HS) occurs when the amount of heat produced by an animal surpasses the animal's capacity to dissipate the heat to its surrounding environment. This imbalance may be caused by variations in a combination of environmental factors (e.g. sunlight, thermal irradiation, air temperature, humidity, and movement) and characteristics of the animal (e.g. species, gender, and rate of metabolism) [1]. Animals experiencing HS tend to reduce their heat production by limiting feed intake, with subsequent negative effects on growth performance. Therefore, HS has been a great concern among scientists and poultry producers for many decades, particularly in arid (dry, hot all year) and in tropical (wet, hot all year) regions of the world, as well as in other climates due to surges in temperature during the spring and summer months. Two major categories of HS, i.e. "acute HS" and "chronic HS" can be distinguished. Acute HS refers to a short and rapid rise in ambient temperature. Chronic HS refers to a high ambient temperature over a long period of time (days to weeks), permitting acclimazation to the environment. Further, chronic HS is categorized as either "cyclic chronic HS," which refers to a limited period of heat exposure followed by comfortable temperature for the rest of the day, or as "constant chronic HS" whereby the animal is continuously confronted with a high ambient temperature. The physiological consequences of HS are numerous and have been reviewed in the past [1-4]. These physiological alterations can be summarized as: increased body core temperature, reduced voluntary feed intake, depressed immunity, alteration of the electrolyte balance and blood $\mathrm{pH}$, impairment in endocrine and reproductive functions, decreased energy availability to cells, alteration in the digestibility and metabolism of various nutrients, disruption in the structure and function of intestinal epithelium, alteration of the normal and protective microbiota, and increased circulatory cortisol and corticosterone levels. A number of mitigation strategies have been proposed and the reader is referred to some concluding reviews [1-6].

More recently, the involvement of HS as an inducer of oxidative stress (OS) has been acknowledged [7-10]. Oxidative stress is defined as the presence of reactive species (RS) in excess of the available antioxidant capacity of animal cells [11]. Many radicals and metabolic substances are described as potentially toxic and are defined as "reactive oxygen/nitrogen/chlorine species" [11]. These substances are highly reactive and can modify several biologically cellular macromolecules, such as proteins, lipids, and nucleic acids (DNA and RNA) [12]. These phenomena contribute to the development of several metabolic dysfunctions, including cell death by causing "oxidative stress" and "oxidative damage" [11].
Oxidized molecules abstract electrons from other molecules, resulting in a chain reaction and, if not controlled, this reaction can cause extensive tissue damage. In addition, OS may alter the redox equilibrium of several cellular redox couples [e.g. reduced glutathione (GSH) and glutathione disulfide (GSSG) and reduced and oxidized thioredoxin] leading to an altered expression of key enzymes in detoxification, antioxidant defense, cell transitions, inflammatory responses, etc.. Cells have evolved defense systems to control the production of RS. These include both non-enzymatic low-molecular weight (e.g. vitamin C, GSH, and uric acid) and enzymatic highmolecular weight [e.g. superoxide dismutase (SOD), glutathione peroxidase (GSH-Px), and arylesterase] compounds. They limit the rate and progression of oxidation and thereby protect cells from oxidative damage. Some low-weight molecular antioxidants are exclusively food derived, e.g. tocopherols. Finally, upon damage, repair mechanisms will be activated.

\section{Oxidative stress is associated with heat stress Heat stress induces mitochondrial dysfunction}

Most cellular energy is produced through oxidative phosphorylation in mitochondria. The process of energy transduction requires the orchestrated action of four major respiratory enzyme complexes (Fig. 1). In normal physiological conditions, an estimated 1-2 \% [12] to 2$4 \%$ [13] of the total oxygen consumed during electron transport is not reduced to water by cytochrome $\mathrm{c}$ oxidase (complex IV), but rather to superoxide due to electron leakage in complexes I and III of the respiratory chain. Cells are equipped with efficient dismutation pathways; i.e. CuZnSOD acts in the intermembrane space (also present in cytosol) and MnSOD acts in the matrix to reduce superoxide to hydrogen peroxide $\left(\mathrm{H}_{2} \mathrm{O}_{2}\right)$. In the presence of ferrous and cuprous ions, $\mathrm{H}_{2} \mathrm{O}_{2}$ can be further reduced to the extremely reactive and dangerous hydroxyl radical $\left(\mathrm{OH}^{\circ}\right.$; Fenton reaction). In contrast to $\mathrm{O}_{2}{ }^{\circ-}$ and $\mathrm{OH}^{\circ}, \mathrm{H}_{2} \mathrm{O}_{2}$ can diffuse into cytosol via membranes, leading to new molecular reactions away from the production site and so reach new cells and tissues. The transmission to neighbouring cells and tissues can occur extremely quickly through several centimeters of tissue in a fraction of a second [12]. It is believed that under normal physiological conditions this reactive oxygen species (ROS) generation is not ultimately harmful and is securely controlled by the antioxidant defense mechanisms [14]. Furthermore, a mild production of ROS is crucial for proper cell function through its signaling actions. Due to its diffusion capacities and higher stability, $\mathrm{H}_{2} \mathrm{O}_{2}$ is the major $\mathrm{ROS}$ acting as a second messenger. In this respect, evidence shows that 2-Cys peroxiredoxin (2-Cys PRX; thioredoxin dependent for regeneration) functions as a regulator in controlling basal 


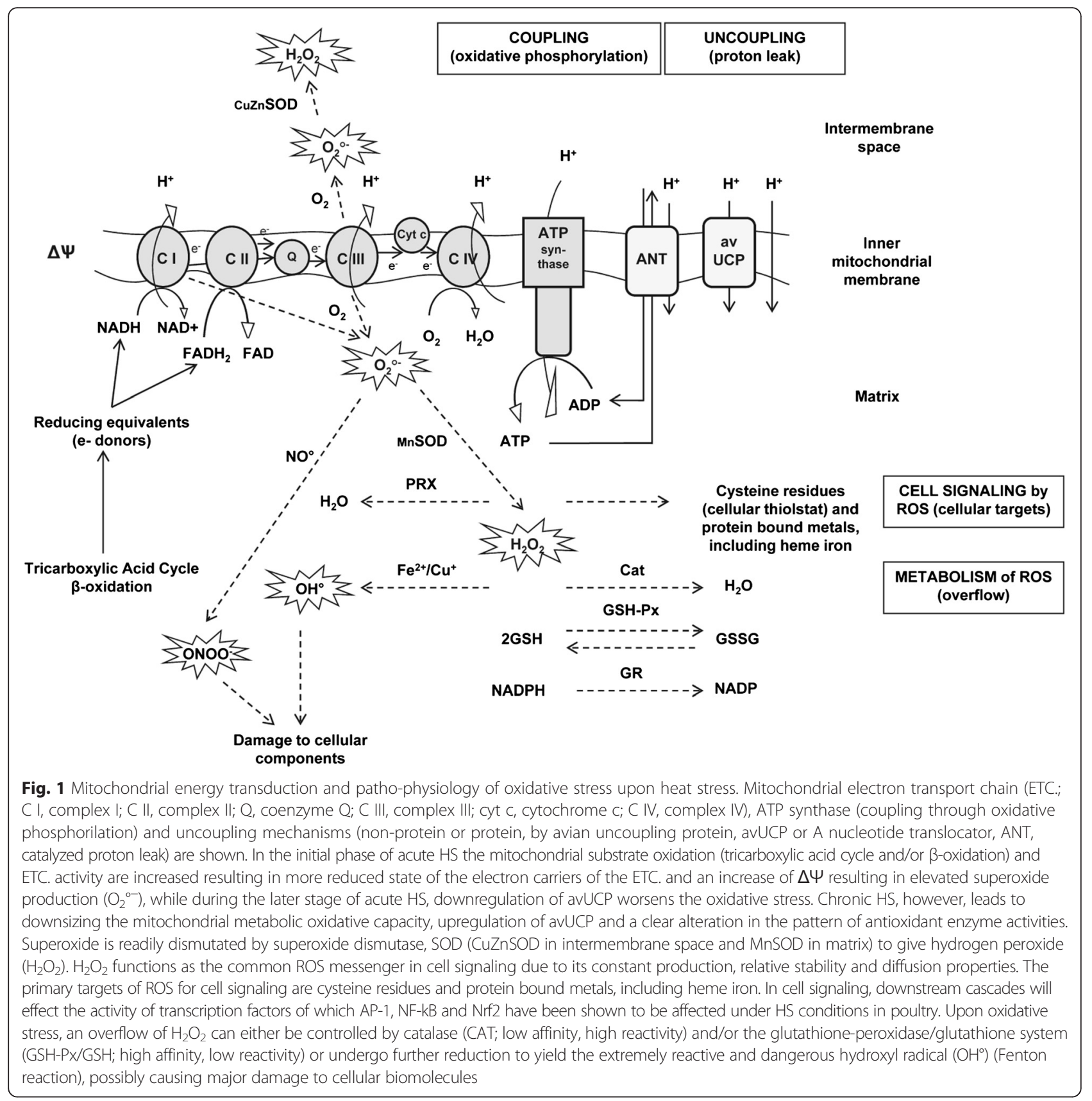

$\mathrm{H}_{2} \mathrm{O}_{2}$ levels in cells by its peroxidase activity (The floodgate hypothesis; [15]).

Although evidence for oxidative stress in heat stressed poultry has been published before, the molecular mechanisms were first described by Toyomizu and coworkers (Graduate School of Agricultural Science, Tohoku University; Sendai, Japan; e.g. Mujahid et al. [9]). The first step in the patho-physiology of HS appears to be an increase in cellular energy demand. Yang et al. [16] noted that promptly after acute heat exposure, cells increase their energy expenditure by 2 fold above normal levels. Mujahid et al. [17] showed that mitochondrial transportation and $\beta$-oxidation of fatty acids were enhanced after $6 \mathrm{~h}$ of acute HS. The latter was associated with elevated blood levels of nonesterified fatty acids. To meet the enhanced energy demand of cells and mitochondrial biogenesis, the production of reducing equivalents and the enzymatic activity of subunits of respiratory chain complexes are increased. Under physiological conditions, electron transport is tightly coupled to oxidative phosphorylation. This means that electrons do not usually flow through the electron transport chain (ETC.) to $\mathrm{O}_{2}$ unless ADP is simultaneously phosphorylated to ATP. 
Increased mitochondrial energy generation is intrinsically associated with an increase in ROS, owing to the fact that ROS production is favored by: 1) high levels of reduction of the electron carriers, particularly the coenzyme Q pool, 2) a large membrane potential $(\Delta \Psi)$, and 3) high mitochondrial oxygen concentrations [18]. With regard to the first, the rate of mitochondrial ROS generation strongly increases with sigmoidal kinetics when the NADH/NAD ${ }^{+}$ ratio is increased. An increase in the $\mathrm{NADH} / \mathrm{NAD}^{+}$ratio dramatically elevates the degree of reduction of complex I reducing its capacity to accept electrons [14]. The increased production of reducing equivalents promotes electron transport in ETC., hence elevating $\Delta \Psi . \Delta \Psi$ is the difference in electric potential between the matrix and mitochondrial intermembrane space and is essential to the action of ATP synthase. According to Kikusato and Toyomizu [19], mitochondrial ROS production is exponentially correlated with elevated $\Delta \Psi$. They found that, in heat stressed broilers, a $2.7 \%$ or $5.3 \mathrm{mV}$ increase in $\Delta \Psi$ in respiratory state IV was accompanied by a $47 \%$ increase in ROS production. This means that a slight increase of $\Delta \Psi$ can have a substantial effect on ROS generation. Kikusato et al. [20] found that increased substrate oxidation (ETC. activity) is primarily responsible for the elevated $\Delta \Psi$ in state IV; however, they were unable to assess whether a decrease in "proton leak" [lower uncoupling through downregulation of avian uncoupling protein (avUCP); see below] happened. A sharp elevation of $\Delta \Psi$ can reduce the efficiency of electron transfer which in turn leads to further leakage of electrons and eventually results in higher superoxide anion formation [21]. Further, it was shown that increased ROS production is independent from substrate supply, indicating that electron leakage and superoxide formation occur in several respiratory complexes [22, 23]. In addition, Kikusato and Toyomizu [19] postulated that the overproduction of ROS in heat stressed birds, when succinate was used as a substrate (yielding NADH), may be caused by reverse electron flow (and leakage) from coenzyme Q to complex I. In contrast, the cause of ROS overproduction upon glutamate oxidation (yielding flavin adenine dinucleotide; FADH2) remained unclear. Tan et al. [24] found that after $3 \mathrm{~h}$ of acute HS, the respiratory enzymes nicotinamide adenine dinucleotide cytochrome $\mathrm{c}$ reductase (NCCR; complex I) and cytochrome c oxidase (CCO; complex IV) showed a temperature-dependent (range of $32^{\circ}$ to $38{ }^{\circ} \mathrm{C}$ ) decrease in activity. This was not so for succinate cytochrome c reductase (SCCR; complex II). Azad et al. [25] observed that in chronic heat exposed chickens, the elevated $\Delta \Psi$ and increased ROS production was found until $\mathrm{d} 9$ and $\mathrm{d} 5$ of HS and not thereafter, meaning that chickens became acclimatized to the stressor. Associated with this acclimation was a decrease in mitochondrial metabolic capacity evidenced by the decrease in 3HADH (3-hydroxyacyl CoA dehydrogenase, a key enzyme in the fatty acid $\beta$-oxidation) and CS [citrate synthase, an enzyme in the tricarboxylic acid cycle (TCA) and an indicator of aerobic metabolism] activity.

\section{Role of uncoupling proteins}

Mitochondria have internal mechanisms to control superoxide production [14]. Uncoupling proteins (UCP) are mitochondrial inner membrane proteins belonging to the family of mitochondrial transporter proteins. Mild uncoupling by UCP, i.e. transferring protons back into the matrix, lowers $\Delta \Psi$ and slightly stimulates electron transport. The complexes become more oxidized and the local concentration of oxygen is reduced. To date, the regulation of UCP remains under discussion. Echtay et al. [26] proposed a simple feedback mechanism in which superoxide is thought to peroxidize membrane phospholipids, forming hydroxynonenal, amongst other lipid peroxidation products, enhancing the action of UCP and adenine nucleotide translocator (ANT). The result is an enhancement of proton backflow. This feedback response limits mitochondrial ROS production upon OS. The picture in poultry is largely unknown. It is conceivable to state that down-regulation of avUCP, hampering mild-uncoupling in heat stressed birds, is a major contributor to the overproduction of ROS. Indeed, it was repeatedly shown that acute HS downregulates the avUCP mRNA expression and protein level in skeletal muscle mitochondria (e.g. [22, 23]). The group of Toyomizu and co-workers showed later that mRNA levels declined after $6 \mathrm{~h}$ of acute HS, while protein levels were significantly lower only for the $12 \mathrm{~h}$ and $18 \mathrm{~h}$ measurements [17]. The same study also revealed that, contrary to avUCP, ANT transcript was not affected by HS. Both avUCP and ANT are known to be up-regulated (uncoupling activity; redox energy is dissipated as heat instead of being used for ATP synthesis) in cold stressed birds and thus play a role in thermogenesis. Apparently, only avUCP is implicated in the HS response (down-regulation of avUCP).

\section{Tissue damage}

Overproduction of ROS in mitochondria can damage proteins, lipids, and DNA, further reducing energy generation efficiency and increasing ROS production in mitochondria. When HS is more severe and/or prolonged than what is justifiable for mitochondrial homeostasis, this can lead to decreased ATP synthesis, cellular calcium dyshomeostasis, and induction of the mitochondrial permeability transition, all of which predispose cells to apoptosis or necrosis. Evidence for mitochondrial damage following HS has been shown by many authors (see below). For example; Mujahid et al. [27] found that in $18 \mathrm{~h}$ heat stressed chickens, plasma and mitochondrial malondialdehyde (MDA) was 2.1- and 2.7-fold higher. They also found that 82 mitochondrial proteins were 
oxidized when compared with control chickens (nonheat-stressed). Mitochondria are particularly vulnerable to oxidative attack because their membranes are rich in polyunsaturated fatty acids and proteins. In addition, OS will impact on the cellular redox environment and interfere with the oxidation/reduction potential of reactive thiols in proteins. The activity and regulation of signaling pathways and transcription factors [e.g. activator protein 1 (AP-1), nuclear factor kappa-light-chain-enhancer of activated $\mathrm{B}$ $(\mathrm{NF}-\mathrm{KB})$ and nuclear factor (erythroid-derived 2)-like 2 (Nrf2); see below] can be affected. It is believed that this series of events is the onset for cellular and tissue damage, causing major physiological and behavioral responses in birds which contribute to reduced productivity.

\section{Effect on cell signaling}

The complex molecular communication network underlying cell biochemistry and function includes numerous components, kinases, phosphatases, and transcription factors, that have been conclusively proven to be sensitive to cellular and tissue redox changes [28]. ROS, whose constitutive generation in cells can thus be amplified in the context of HS, are important triggers and modulators of cell signaling and consequently cell behavior. Several redox-sensitive downstream pathways culminate in the activation of transcription factors, of which AP-1, NF$\kappa B$, and Nrf2 have been shown to be affected under HS conditions in poultry. AP-1 acts as a modulator of the expression of various genes in response to biological and environmental stimuli such as OS (phase II antioxidant defense such as glutathione S-transferase and $\mathrm{NAD}(\mathrm{P}) \mathrm{H}$ oxidoreductase), whereas NF- $\mathrm{KB}$ is principally involved in pro-inflammatory responses. Both transcription factors are involved in cell survival, differentiation, and growth. Upon activation, Nrf2 can bind specifically to the antioxidant response element (ARE) of the genome, which is located in the promoter region of stress-induced genes. Nrf2 induces the initiation of phase I and II enzymes. Linked with HS in poultry, cyclic chronic HS (35-day-old Japanese quails were exposed for 12 weeks to $34{ }^{\circ} \mathrm{C}$ for $8 \mathrm{~h} / \mathrm{d}$ followed by $22^{\circ} \mathrm{C}$ ) has been shown to increase hepatic expression of cyclooxygenase-2, heat-shock proteins (HSP), AP-1 components (c-Jun and c-Fos), and NF- $k B$, and to reduce expression of Nrf2 [29, 30]. The latter corroborated with decreased antioxidant enzyme activities. Nevertheless, from other studies it appears that the exact outcome of the (de)activation of transcription factors during HS is hard to understand. For example, it has been shown that acute HS in pigs led to oxidative damage and up-regulation of antioxidant enzymes in red semitendinosus fibres (oxidative muscle; high mitochondrial density), but did not trigger a pro-inflammatory response, suggesting that the up-regulation of NF-kB-dependent genes upon HS is more complex and highly dependent on the stressor [31].
Hence, a better understanding of the impact of different levels of HS on cell signaling warrants attention; not in the least because many antioxidant phytochemicals appear to interact with cell signaling cascades and/or with transcription factors directly (e.g. [29]). In the context of HS, the heat-shock response needs discussion as well. Following increases in body temperature, cellular proteins may become unfolded and cell functions be compromized. The heat-shock response, through activation of heat-shock transcription factors and the elevated expression of inducible heat-shock proteins (HSP) and molecular chaperones, protects the cell against the accumulation of non-native proteins. HSP interact with those proteins to hold them properly together and retain them functional, hence exhibiting a major contribution to cell integrity under these stress conditions. It has been documented that exposing poultry to HS increases the concentrations of HSP70 and HSP90 [30, 32, 33]. Barret et al. [34] stated that ETC. dysfunction activates a heat-shock protein response, and that this response is mediated by OS. Inhibition of HSP70 expression in intestinal mucosa by quercetin led to a more severe extent of stress, as there was a significant elevation of serum corticosterone and heterophil:lymphocyte ratio, and a reduction in the enzymatic antioxidant response in acute HS chickens [33]. Pamplona and Costantini [14] outlined that quantification of stress response mediated by HSP is a promising biomarker to evaluate how an organism can maintain cellular functioning under environmental challenges and protein denaturing conditions. In this regard, $\mathrm{Gu}$ et al. [33] showed nicely that in acutely heat stressed broilers a higher HSP70 response correlated with a better antioxidant defence.

\section{Oxidative stress upon acute and chronic heat stress}

A literature survey was performed and all studies that included a negative control (non-heat-stressed birds for comparison) were selected. Full details can be found in Additional file 1: Table S1 and Additional file 2: Table S2, addressing studies that investigated the effects of acute and chronic HS on the oxidative status of poultry, respectively (references included in Supplementary Material S1 and S2). Elevated levels of lipid peroxidation products (aldehydes, hydrocarbons, and isoprostanes) and protein carbonyls in serum, plasma, and tissues have been recognized as an index of OS. The elevation of MDA does not occur to the same extent in acute and chronic HS. For example, acute HS (30-day-old broilers were exposed for $5 \mathrm{~h}$ to $40 \pm 1{ }^{\circ} \mathrm{C}$; [35]) exhibited a 4-fold increase in MDA, whereas chronic HS (14-day-old broilers were exposed for $14 \mathrm{~d}$ to a cyclic chronic $\mathrm{HS}$ at $32{ }^{\circ} \mathrm{C}$ for $8 \mathrm{~h} / \mathrm{d}$ followed by $24{ }^{\circ} \mathrm{C}$; [36]) showed a 1.2- to 1.5-fold increment in MDA. Depending on the severity and duration of HS, the antioxidant system 
and associated enzymes behave differently. Typically, after acute HS, the activities of antioxidant enzymes (CAT, GSHPx, and SOD) are increased sharply to protect cells against surplus superoxide formation. On the other hand, inconsistent results have been reported in chronic HS. Pamok et al. [37] reported that exposing 28-day-old broilers for $21 \mathrm{~d}$ to a constant chronic $\mathrm{HS}$ at $38 \pm 2{ }^{\circ} \mathrm{C}$ leads to an increase in GSH-Px activity in erythrocytes until d11 of HS, while Seven et al. [38] found decreased GSH-Px activity in blood, liver, kidney, and heart from constant chronic HS exposed broilers (1-day-old, at $34{ }^{\circ} \mathrm{C}$ for $41 \mathrm{~d}$ ). Differences in antioxidant enzyme activities might largely depend on the HS conditions, species, and tissue. Interestingly, Sahin et al. [29] found that, in chronic heat stressed quail, a reduced hepatic SOD, GSH-Px, and CAT activity corroborated with a reduction in Nrf2 expression. Another more clear difference exists between the acute and chronic HS response. Acute HS down-regulates avUCP synthesis leading to overproduction of ROS, whereas chronic HS works in the opposite way and up-regulates UCPs synthesis in an attempt to lower ROS production. Down-regulating avUCP and mRNA abundance upon acute HS occurred at all times until $18 \mathrm{~h}$ after starting acute HS [17]. Dridi et al. ([39]; 28-day-old ISA JV broilers were exposed for $10 \mathrm{~d}$ to $32{ }^{\circ} \mathrm{C}$ ) and Azad et al. ([36]; 14-day-old Ross broilers were exposed for $14 \mathrm{~d}$ to constant chronic $\mathrm{HS}$ at $32{ }^{\circ} \mathrm{C}$ or $34{ }^{\circ} \mathrm{C}$ or to cyclic chronic $\mathrm{HS}$ at $32{ }^{\circ} \mathrm{C}$ for $8 \mathrm{~h} / \mathrm{d}$ followed by $24{ }^{\circ} \mathrm{C}$ ) showed that chronic HS enhanced avUCP transcript levels in pectoralis superficial muscle mitochondria by $71 \%$ and $100 \%$, respectively. It has been reported that acute HS (16-day-old Cobb broilers were exposed for $18 \mathrm{~h}$ to $34{ }^{\circ} \mathrm{C}$; [17]) increases the activity of $3 \mathrm{HADH}$ and CS, thereupon, stimulating metabolic oxidation capacity in mitochondria, leading to higher levels of mitochondrial superoxide, hence inducing OS. These increments were time-dependent; only after $6 \mathrm{~h}$ of HS was the activity of these enzymes significantly enhanced. After 12 and $18 \mathrm{~h}$ of HS, they were reduced to the levels of those of a nonheated group. On the contrary, Azad et al. [36] showed that exposing 14-day-old Ross broilers for $14 \mathrm{~d}$ to either of two constant chronic $\mathrm{HS}$ situations at $32{ }^{\circ} \mathrm{C}$ or $34^{\circ} \mathrm{C}$ or to cyclic chronic HS at $32{ }^{\circ} \mathrm{C}$ for $8 \mathrm{~h} / \mathrm{d}$ followed by $24{ }^{\circ} \mathrm{C}$, decreased the activities of 3HADH and CS.

A number of chronic HS studies have been executed at the laboratory of Sahin and co-workers (Additional file 2: Table S2), all of which show higher MDA concentrations and lower antioxidant components (e.g. vitamins C, E, A, and co-factors $\mathrm{Zn}, \mathrm{Mn}, \mathrm{Cu}, \mathrm{Se}$ ) in tissues of broilers and Japanese quails. For instance, Sahin et al. [40] showed that chronic exposure to high temperature (10-day-old Japanese quails were exposed to $34{ }^{\circ} \mathrm{C}$ for $8 \mathrm{~h} / \mathrm{d}$ followed by $22{ }^{\circ} \mathrm{C}$ for $32 \mathrm{~d}$ ) decreased serum ascorbic and tocopherol concentrations by $40 \%$ and $29 \%$.
Based on their reports, following chronic HS, components of the animal's antioxidant system became depleted. This supports the contention that the animal's antioxidant system needs to be re-enforced upon chronic HS. Further, Gursu et al. [41] reported that HS (10-day-old Japanese quails were exposed to cyclic chronic $\mathrm{HS}$ at $34{ }^{\circ} \mathrm{C}$ for $8 \mathrm{~h} / \mathrm{d}$ for $30 \mathrm{~d}$ ) reduces the activity of arylesterase and paraoxonase in serum and that antioxidant supplementation (vitamin $\mathrm{C}$ and folic acid) inverts this reduction. Reducing the activity of arylesterase and paraoxonase following a shorter time of chronic HS has also been reported (22-day-old Hubbard broilers were exposed to cyclic chronic $\mathrm{HS}$ at $35 \pm 1{ }^{\circ} \mathrm{C}$ for $8 \mathrm{~h} / \mathrm{d}$ for $20 \mathrm{~d}$, [42]. Gursu et al. [41] noted that these enzymes show free radical scavenging activity. Furthermore, it was found that serum homocysteine increases and folic acid and vitamin B12 decreases in chronic HS (e.g. [8, 43]), indicating enhanced conversion of methionine to cysteine to support GSH replenishment. In these reports, basal serum homocysteine levels ranged between 9.5 and $17 \mu \mathrm{mol} / \mathrm{L}$ and increased to levels between 21.1 and $24.0 \mu \mathrm{mol} / \mathrm{L}$ in heat stressed Japanese quails (increase between $+41 \%$ to $+122 \%$ ). Two reports indicated an increase in GSH in the liver, the main site for GSH synthesis. Ramnath et al. [44] found an increase during 5 to $10 \mathrm{~d}$ of cyclic chronic heat stressed male Gramapriya chickens (28-day-old, at $40 \pm 1{ }^{\circ} \mathrm{C}$ for $4 \mathrm{~h} /$ d, $\mathrm{RH}=80 \% \pm 5 \%$ ). Willemsen et al. [45] showed higher hepatic total GSH levels and lower GSH/GSSG ratios in 4 week constant heat stressed Ross male broilers (14-day-old, $\left.32{ }^{\circ} \mathrm{C}\right)$. These authors also found that plasma uric acid levels were increased, which corroborates with the result of Azad et al. [36]. It appears that birds adapt to chronic HS by up-regulation of levels of endogenous antioxidants such as GSH and uric acid, in line with what has been shown in other stress models (e.g. [46]; free-ranging in combination with severe feed restriction).

\section{Potential of antioxidants towards preventing/ reducing oxidative stress in heat stressed poultry} Strategies to reduce mitochondrial dysfunction in heat stressed broilers

Based on the mechanisms leading to mitochondrial dysfunction outlined above, 3 approaches are suggested here in order to deal with mitochondrial dysfunction in heat stressed birds; i.e. 1) reduce the membrane potential (e.g. mild uncoupling by using uncouplers or up-regulating avUCP), 2) increase ETC. efficiency (e.g. supplementation with coenzyme Q), or 3) enhance ROS detoxifying capacity (e.g. SOD activity, antioxidants acting either directly or indirectly through the activation of cell signaling pathways). The first strategy might appear ambigous. If the aim 
is to reduce the membrane potential through uncoupling, then substrates are oxidized producing heat instead of usable energy in the form of ATP. This might seem contra productive because: 1) this heat production may further enhance hyperthermia and 2) inefficient use of ingested feed may accentuate one of the key issues in heat stressed poultry, i.e. the reduced feed intake. Conversely, Azad et al. [47] found that using a mild uncoupler [cashew nut shell liquid (CNSL) as a source of anacardic acid] in chronic heat stressed broilers, increased feed consumption and weight gain and argued that this uncoupling might trigger enhanced feed intake. Although CNSL was not able to mitigate muscle MDA and $\mathrm{H}_{2} \mathrm{O}_{2}$ formation in the study of Azad et al. [47], it showed a mild-uncoupling effect in mitochondria in the study of Toyomizu et al. [48]. It remains equivocal whether selective uncoupling could, perhaps temporarily, relieve heat stressed poultry from OS upon short episodes of high environmental temperatures.

Coenzyme Q (also called ubiquinone) has received extensive interest in the scientific community. It acts both as an electron carrier in the ETC. and as an oil-soluble antioxidant within membranes and other lipophilic matrices. Coenzyme Q plays a crucial role in the ETC. since it functions as an electron carrier from complex I and II to complex III. Its antioxidant function is widely acknowledged; it inhibits both the initiation and propagation of lipid and protein oxidation and regenerates other antioxidants such as vitamin E. It is conceivable to assume that an increase in the bioavailability of coenzyme Q should be beneficial to heat stressed broilers. Coenzyme $\mathrm{Q}$ is biosynthesized in the body and can be obtained from food, in particular meat, fish, and vegetable oils are rich sources. It is assumed that biosynthesis is the major source. Broiler diets fortified with coenzyme $Q$ have been shown to reduce the incidence of ascites (pulmonary hypertension syndrome) and the mortality of broilers [49], and this was attributed to improved ETC. efficiency upstream of coenzyme $Q$ and higher hepatic mitochondrial antioxidant capabilities. Similar to heat stress, ascites has been shown to be associated with mitochondrial dysfunction [50, 51]. Enhanced performance upon coenzyme Q supplementation was also found in broilers under high altitude induced hypoxia [52].. Similarly, the role of L-carnitine should be recalled. L-carnitine plays a key role in energy metabolism of cells, mainly, by transferring acyl groups from cytoplasm to mitochondrial matrix for $\beta$-oxidation [53]. Supplementary L-carnitine demonstrated antioxidant effects in thermoneutral broilers [54], low-temperature stressed broilers, inducing ascites [49, 55] and high altitude broilers, inducing ascites [56], by virtue of its free radical scavenging properties [57]. To date, coenzyme Q and L-carnitine have not been tested in heat stressed poultry.

Enhancing ROS detoxifying capacity remains the primary target in heat stressed broilers, which can be achieved either by 1) scavenging ROS, 2) inhibiting enzymatic processes that lead to the formation of ROS or by chelating trace elements involved in ROS formation, or 3) by upregulating and protecting endogenous antioxidant defenses. In line with this, the possible role of the endogenous antioxidant GSH needs attention. Bioavailability of sufficient L-cysteine, the most limiting amino acid in GSH biosynthesis, guarantees appropriate synthesis of GSH, which in turn can be synthesized from methionine. Del Vesco et al. [58], Surai [59] showed that a diet in which methionine met the nutritional requirements resulted in lower OS upon acute HS in meat quail as compared to a diet deficient in methionine. Gursu et al. [41] and Sahin et al. [8] found that supplementing the diets of Japanese quail under conditions of cyclic chronic HS with $1 \mathrm{mg} / \mathrm{kg}$ folic acid (which plays a role in the methylation of homocysteine into methionine, amongst other functions) partially inverted the reductions in basal serum paraoxonase and arylesterase activities, vitamins $\mathrm{A}, \mathrm{B}_{12}, \mathrm{C}, \mathrm{E}$, and folic acid, and reduced the increase of MDA in tissues. Attention is warranted in the choice of L-cysteine source (L-cysteine, L-cystine, or N-acetyl-L-cysteine) and the dietary level and source of methionine [45]. Many antioxidant enzymes have metals as a co-factor; therefore, dietary supply of these co-factors also needs thorough attention in situations of HS (e.g. [60]). The potential of the antioxidant vitamins $\mathrm{A}, \mathrm{E}$, and $\mathrm{C}$ are only briefly mentioned here; the reader is referred to the reviews of Khan et al. [61], Khan et al. [62], Lin et al. [5], and Mujahid [63] for an illustration of their established beneficial properties for heat stressed poultry. Some studies on these vitamins can also be found in Table 1; however, these are limited to studies in which these vitamins were applied as a comparison to the effect of phytochemicals. Vitamin $\mathrm{C}$ and vitamin $\mathrm{E}$ are the antioxidants of first choice to combat heat stress and are provided through the drinking water and feed, respectively, owing to their relatively short and long half-life in the animal's body and different solubility properties.

\section{Antioxidant and favorable properties of phytochemicals}

A literature survey was performed to collect data on the effects of feeding supplementary phytochemicals with demonstrated antioxidant properties to poultry under HS on oxidative status parameters (Table 1). The effects on other physiological responses and bird performance are not considered here. Phytochemicals are here defined as any product derived from plants containing secondary plant metabolites as active principles (e.g. dried plant material, extract, essential oil, pure isolated compound). All experiments were conducted in chronic HS models except one case. Surprisingly few studies have been reported in the literature, most of which showed a positive outcome. Two herbs used in traditional Chinese medicine were shown to reduce MDA in the tissues and egg yolk of 
Table 1 Effects of supplementary phytochemicals on oxidative status of poultry under cyclic chronic heat stress (CyCHS), constant chronic heat stress (CoCHS), and acute heat stress (AHS) (the birds were sampled at the end of HS, unless otherwise stated). Signicant effects on parameters of oxidative status are given for dietary treatments under HS conditions as compared to a heat stressed control (i.e. Cont. or T1). In case, both a non heat stressed (non supplemented) and heat stressed (non supplemented) control are included, data are used to confirm the presence of heat stress

Heat stress model
At d 10 of age for $32 \mathrm{~d}$ were exposed to:
1. Cont. at $22^{\circ} \mathrm{C}$
2. CyCHS at $34{ }^{\circ} \mathrm{C}$ for $8 \mathrm{~h} / \mathrm{d}$, (RH $\left.=44 \%\right)$
A $2 \times 4$ factorial design
At wk 60 of age for $28 \mathrm{~d}$ all groups were exposed
to $\mathrm{CoCHS}$ at $32^{\circ} \mathrm{C}$

to $\mathrm{CoCHS}$ at $32^{\circ} \mathrm{C}$

At $\mathrm{d} 10$ of age for $32 \mathrm{~d}$ were exposed to:

1. Cont. at $22^{\circ} \mathrm{C},(\mathrm{RH}=57 \%)$

2. $\mathrm{CyCHS}$ at $34^{\circ} \mathrm{C}$ for $8 \mathrm{~h} / \mathrm{d},(\mathrm{RH}=42 \%)$

A $2 \times 4$ factorial design

At $\mathrm{d} 0$ of age for $49 \mathrm{~d}$ all groups were exposed to $\mathrm{CoCHS}$ at $38.6 \pm 1.30^{\circ} \mathrm{C},(\mathrm{RH}=64 \pm 6.0 \%)$

On $d 21$ and 35 (RBS) and d 49 (other tissues) after starting HS birds were sampled

At $\mathrm{d} 3$ of age for $39 \mathrm{~d}$ all groups were exposed to CoCHS at $32 \pm 1{ }^{\circ} \mathrm{C},(\mathrm{RH}=44 \pm 6 \%)$

On d 18 and 39 after starting HS birds were sampled

At $1 \mathrm{~kg} \mathrm{BW}$ for $20 \mathrm{~d}$ were exposed to:

1. Cont at $30^{\circ} \mathrm{C},(\mathrm{RH}=65 \%)$

2. CyCHS at $40 \pm 1{ }^{\circ} \mathrm{C}$ for $5 \mathrm{~d}$ out of $20 \mathrm{~d}$ for $4 \mathrm{~h} / \mathrm{d}$,

$(\mathrm{RH}=80 \pm 5 \%)$

3. CyCHS at $40 \pm 1^{\circ} \mathrm{C}$ for $10 \mathrm{~d}$ out of $20 \mathrm{~d}$ for $4 \mathrm{~h} / \mathrm{d}$

$(\mathrm{RH}=80 \pm 5 \%)$

A $3 \times 2$ factorial design

At $\mathrm{d} 10$ of age for $32 \mathrm{~d}$ were exposed to:

1. Cont. at $22^{\circ} \mathrm{C}$

2. CyCHS at $34^{\circ} \mathrm{C}$ for $8 \mathrm{~h} / \mathrm{d}$

A $2 \times 3$ factorial design

At $\mathrm{d} 0$ of age for $41 \mathrm{~d}$ were exposed to:

1. Cont. at conventional temperature scheme

(only Cont. diet)

2. $\mathrm{CoCHS}$ at $34^{\circ} \mathrm{C}$
Poultry species and diets

Japanese quails; dietary treatments starting at $d 10$ of age

1. Cont.; 2. Cont. + genistein (GN) at $200 \mathrm{mg} / \mathrm{kg} ; 3$. Cont. + GN

at $400 \mathrm{mg} / \mathrm{kg} ; 4$. Cont. + GN at $800 \mathrm{mg} / \mathrm{kg}$

Hy-Line laying hens; dietary treatments starting at wk 60 of age 1. Cont.; 2. Cont. + Schisandra chinensis (SC) at $10 \mathrm{~g} / \mathrm{kg}$;

3. Cont. + Ligustrum lucidum (LL) at $10 \mathrm{~g} / \mathrm{kg}$

Japanese quails; dietary treatments starting at $d 10$ of age 1. Cont.; 2. Cont. + lycopene at $50 \mathrm{mg} / \mathrm{kg} ; 3$. Cont. + lycopene $100 \mathrm{mg} / \mathrm{kg} ; 4$. Cont. + lycopene at $200 \mathrm{mg} / \mathrm{kg}$

Cobb broilers; dietary treatments starting at $\mathrm{d} 0$ of age 1. Cont., T1; 2. Cont. + vitamin E at 200 mg/kg, T2; 3. Cont. + dry powdered leaves of Mentha longifolia (DPLM) at $10 \mathrm{~g} / \mathrm{kg}, \mathrm{T3}$ 4. Cont. + DPLM at $30 \mathrm{~g} / \mathrm{kg}, \mathrm{T4} ; 5$. Cont. + mix of Emblica officinalis fruit, vitamin $\mathrm{E}$ and electrolytes at $1 \mathrm{~g} / \mathrm{kg}$. T5

Male Arbor Acres broilers; dietary treatments starting at d 3 of age

1. Cont. T1; 2. Cont. + vitamin C at $200 \mathrm{mg} / \mathrm{kg}, \mathrm{T} 2 ; 3$. Cont. + extract from dried fruits of Forsythia suspensa (FSE) at $100 \mathrm{mg} / \mathrm{kg}$, T3

Male Gramapriya egg type domestic chickens (India); dietary treatments starting $10 \mathrm{~d}$ prior to $\mathrm{CyCHS}$ and during $\mathrm{CyCHS}$ or for $20 \mathrm{~d}\left(\right.$ Cont. at $\left.30^{\circ} \mathrm{C}\right)$

1. Cont:; 2. Cont. + Brahma Rasayana extract; Ayurvedic polyherbal preparation in which Emblica officinalis and Terminalia chebula are two major ingredients accounting $\geq 75 \% \mathrm{~W} / \mathrm{W}$ (BR) at $2 \mathrm{~g} / \mathrm{kg}$ BW

Japanese quails; dietary treatments starting at $\mathrm{d} 10$ of age 1. Cont.; 2. Cont. + epigallocatechin-3-gallate (EGCG) at $200 \mathrm{mg} / \mathrm{kg}$; 3. Cont. + EGCG at $400 \mathrm{mg} / \mathrm{kg}$

Ross 308 broilers; dietary treatments starting at $\mathrm{d} 0$ of age 1. Cont., T1; 2. Cont. + vitamin C at $250 \mathrm{mg} / \mathrm{kg}$, T2; 3. Cont + ethanol extract of propolis (EEP) at $0.5 \mathrm{~g} / \mathrm{kg}, \mathrm{T} 3 ; 5$. Cont + EEP at $1 \mathrm{~g} / \mathrm{kg}$, T4; 5. Cont. + EEP at $3 \mathrm{~g} / \mathrm{kg}$, T5
Significant results

Reference

Serum, liver: MDA $\downarrow$ by GN vs. Cont

serum: homocysteine $\downarrow$ by GN vs. Cont.;

vitamins $C$, E, A $\uparrow$ by GN vs. Cont.

Serum, liver, heart, egg yolk: MDA $\downarrow$ by SC and LL vs. Cont. Serum, kidney, liver: GR activity $\uparrow$ by SC and LL vs. Cont.

Heart: GR activity $\uparrow$ by LL vs. Cont.

Serum, liver, heart: MDA linear $\downarrow$ by lycopene vs. Cont

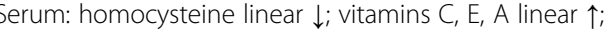
all by lycopene vs. Cont.

RBC: MDA $\downarrow$ by T2, T3, T4, T5 vs. T1 at $d 21$ and 35; GSH content $\uparrow$ by $T 3, T 4, T 5$ vs. T1 at d 35; CAT, SOD GR activity $\uparrow$ by $T 2, T 3, T 4, T 5 \mathrm{Vs}$. T1 at $\mathrm{d} 21$ and 35 Heart, liver, brain cortex: MDA $\downarrow$ by T2, T3, T4, T5 vs. T1 at $d$ 49: SOD, GR activity $\uparrow$ by $T 2, T 3, T 4, T 5$ vs. T1 at $d 49$

Serum: TAOC $\uparrow$ by T2, T3 vs. T1 at $d 18$ and 39; MDA $\downarrow$ by T2, T3 vs. T1 at $d 18$ and 39; SOD activity $\uparrow$ by T3 vs. $T 1$ at $\mathrm{d} 18$

Liver: MDA $\downarrow$ by $T 3$ vs. $T 1$ at $d$ 39; SOD activity $\uparrow$

by T2, T3 vs. T1 at 18 and by T3 vs. T1 at $d 39$

Muscle: SOD activity $\uparrow$ by T3 vs. T1 at d 39; MDA $\downarrow$ by $T 2, T 3$ vs. T1 at $d 39$

RBC: CAT and SOD activities $\uparrow$ by BR vs. respective Cont Serum, liver: MDA $\downarrow$ by BR vs. respective Cont. Liver: CAT, SOD, GSH-Px, GR activities $\uparrow$ by BR vs. respective Cont.

Serum, liver: MDA linear $\downarrow$ by EGCG vs. Cont. Serum: vitamins C, E, A $\uparrow$ by EGCG vs. Cont.

Plasma: SOD activity $\downarrow$ by T2, T3, T4, T5 vs. T1; MDA $\downarrow$ by $\mathrm{T2}, \mathrm{T} 5 \mathrm{vs}$. T1; CAT activity $\downarrow$ by $T 5 \mathrm{v}$. T1: GSH-Px $\uparrow$ by $\mathrm{T} 2, \mathrm{~T} 4, \mathrm{~T} 5 \mathrm{vs}$. $\mathrm{T} 1$

Liver: MDA $\downarrow$ by T5 vs. T1; CAT activity $\downarrow$ by T2, T5 v. T1, GSH-Px $\uparrow$ by T2, T3, T4, T5 vs. T1 
Table 1 Effects of supplementary phytochemicals on oxidative status of poultry under cyclic chronic heat stress (CyCHS), constant chronic heat stress (CoCHS), and acute heat stress (AHS) (the birds were sampled at the end of HS, unless otherwise stated). Signicant effects on parameters of oxidative status are given for dietary treatments under HS conditions as compared to a heat stressed control (i.e. Cont. or T1). In case, both a non heat stressed (non supplemented) and heat stressed (non supplemented) control are included, data are used to confirm the presence of heat stress (Continued)

At 18 of age for $27 \mathrm{~d}$ were exposed to:

1. Cont. at $26 \pm 2^{\circ} \mathrm{C}$

2. $\mathrm{CyCHS}$ at $38 \pm 2^{\circ} \mathrm{C}$ for $6 \mathrm{~h} / \mathrm{d}$

On $1,7,14,21$ after starting HS birds were sampled

At $\mathrm{d} 0$ for $42 \mathrm{~d}$ all groups were exposed to $\mathrm{CoCHS}$ at $32.86 \pm 0.68^{\circ} \mathrm{C}$

On d 21 and 42 after starting HS birds were sampled

At d 35 for 12 wk were exposed to:

1. Cont. at $22^{\circ} \mathrm{C}$

2. CyCHS at $34^{\circ} \mathrm{C}$ for $8 \mathrm{~h} / \mathrm{d}$

A $2 \times 3$ factorial design

At d 35 for 12 wk were exposed to:

1. Cont. at $22^{\circ} \mathrm{C}$

2. CyCHS at $34^{\circ} \mathrm{C}$ for $8 \mathrm{~h} / \mathrm{d}$

A $2 \times 3$ factorial design

At d 35 for 12 wk were exposed to:

1. Cont. at $22^{\circ} \mathrm{C}$

2. CyCHS at $34^{\circ} \mathrm{C}$ for $8 \mathrm{~h} / \mathrm{d}$

A $2 \times 3$ factorial design

At $\mathrm{d} 19$ for $5 \mathrm{~d}$ were exposed to:

1. Cont. at $24^{\circ} \mathrm{C}$

2. $\mathrm{CoCHS}$ at $34^{\circ} \mathrm{C}(\mathrm{RH}=55 \%)$

A $2 \times 4$ factorial design

At $\mathrm{d} 28$ for $10 \mathrm{~d}$ all groups were exposed to $\mathrm{CyCHS}$ at $34^{\circ} \mathrm{C}$ for $5 \mathrm{~h} / \mathrm{d}$ followed by $22^{\circ} \mathrm{C}$, $(\mathrm{RH}=50 \%)$

At $\mathrm{d} 42$ for $15 \mathrm{~d}$ were exposed to:

1. Cont. at $24 \pm 2{ }^{\circ} \mathrm{C}$ (only Cont.diet)

2. CyCHS at $37 \pm 2{ }^{\circ} \mathrm{C}$ for $8 \mathrm{~h} / \mathrm{d}$ followed by $24 \pm 2{ }^{\circ} \mathrm{C}$
Male broilers; dietary treatments starting at $d 18$ of age

1. Cont., T1; 2 . Cont. + polyphenols extracted from Tamarindus indica seed coat (PTSCE) at $100 \mathrm{mg} / \mathrm{kg}, \mathrm{T} 2 ; 3$. Cont. + PTSCE at $200 \mathrm{mg} / \mathrm{kg}$, T3; 4. Cont. + PTSCE at $300 \mathrm{mg} / \mathrm{kg}, \mathrm{T} 4 ; 5$. Cont. + PTSCE at $400 \mathrm{mg} / \mathrm{kg}$, T5; 6. Cont. + PTSCE at $500 \mathrm{mg} / \mathrm{kg}$, T6

Cobb broilers; dietary treatments starting at $\mathrm{d} 0$ of age 1. Cont., T1; 2. Cont. + polyherbal mix Stresroak (fruits and leaves from different herbs, containing vitamin $\mathrm{C}$ and flavonoids as major active principles) at $1 \mathrm{~g} / \mathrm{kg}, \mathrm{T} 2 ; 3$. Cont. + vitamin C at $100 \mathrm{mg} / \mathrm{kg}$, T3

Female Japanese quails; dietary treatments starting at $d 35$ of age 1. Cont.; 2. Cont. + epigallocatechin-3-gallate (EGCG) at

$200 \mathrm{mg} / \mathrm{kg} ; 3$. Cont. + EGCG at $400 \mathrm{mg} / \mathrm{kg}$

Female Japanese quails; dietary treatments starting at $d 35$ of age 1. Cont.; 2. Cont. + tomato powder (TP) at $25 \mathrm{~g} / \mathrm{kg} ; 3$. Cont. + TP at $50 \mathrm{~g} / \mathrm{kg}$

Female Japanese quails; dietary treatments starting at d 35 of age 1. Cont.; 2. Cont. + Berberis vulgaris root extract (BVE) at

$200 \mathrm{mg} / \mathrm{kg}: 3$. Cont. + BVE at $400 \mathrm{mg} / \mathrm{kg}$

Ross 308 broilers; dietary treatments starting at $\mathrm{d} 0$ of age 1. Cont $\mathrm{T} 1$; 2 Cont + cashew nut shell liquid (CNSL, $75 \%$ anacardic acids) at $2 \mathrm{mg} / \mathrm{kg}$, T2; 3. Cont. + grape seed extrac (GSE, $40 \%$ proanthocyanidins) at $40 \mathrm{mg} / \mathrm{kg}$, T3; 4. Cont. + electrolysed reduced water (ERW, pH 8.1 to 10.1; Eh -160 to $-607 \mathrm{mV}$ ), T4

Ross 308 broilers; dietary treatments starting at $\mathrm{d} 25$ of age 1. Cont., T1: 2. Cont. + Curcuma xanthorrhiza essential oil (CXEO) at $200 \mathrm{mg} / \mathrm{kg}, \mathrm{T} 2 ; 3$. Cont. + CXEO at $400 \mathrm{mg} / \mathrm{kg}, \mathrm{T} 3 ; 4$. Cont. + emon peel extract (LPE) at $200 \mathrm{mg} / \mathrm{kg}, \mathrm{T} 4 ;$ 5. Cont. + LPE at $400 \mathrm{mg} / \mathrm{kg}, \mathrm{T} 5 ; 2$. Cont. + orange peel extract (OPE) at $200 \mathrm{mg} / \mathrm{kg}$, T6; 3. Cont. + OPE at $400 \mathrm{mg} / \mathrm{kg}$, 17

Female Xuefeng black-boned chickens; dietary treatments starting at $d 42$ of age

1. Cont.; 2. Cont. $+200 \mathrm{mg} / \mathrm{kg}$ resveratrol; 3. Cont. +400 mg/kg resveratrol; 4 . Cont $+600 \mathrm{mg} / \mathrm{kg}$ resveratrol
Muscle: MDA $\downarrow$ by T4, T5 vs, T1. GSH $\downarrow$ by T2, T4, T5 v T1

Kidney: CAT activity $\downarrow$ by T2, T5 $v$. T1; GSH $\downarrow$ by T4 $v$. T1;

GSH-Px $\uparrow$ by $T 2, T 3, T 4, T 5$ vs. T

Heart: CAT activity $\downarrow$ by T5 $v$. T1; GSH $\downarrow$ by T5 $v$. T1 GSH-Px $\uparrow$ by T2, T3, T4, T5 vs. T

Serum: MDA $\downarrow$ by $T 5 v$. T1 at $d$ 1: MDA $\uparrow$ by $T 2$.

T3 vs. T1 at $d 7$

Serum (in average): MDA $\uparrow$ by $T 2$ vs. T

Serum: SOD activity $\uparrow$ by $T 2, T 3$ vs. $T 1$ at $d 21$; SOD activity $\uparrow$ by $T 2$ vs. T1 at $\mathrm{d} 42$; GR activity $\uparrow$ by $\mathrm{T} 2$,

3 vs. $T 1$ at $d 21$ and 42

Liver: MDA, NF-kB linear $\downarrow$ by EGCG vs. Cont.; CAT,

SOD, GSH-Px activity, Nrf2 inear $\uparrow$ by EGCG vs. Cont

Liver: MDA, NF-kB linear $\downarrow$ by TP vs. Cont;; CAT, SOD,

GSH-Px activity, Nrf2 inear $\uparrow$ by TP vs. Cont

Liver: MDA, HSP70, NF-kB linear $\downarrow$ by EGCG vs. Cont:; CAT, SOD, GSH-Px activity, HO-1, Nrf2 linear $\uparrow$ by EGCG vs. Cont

Pectorial superficialis muscle: $\mathrm{H}_{2} \mathrm{O}_{2} \downarrow$ by $\mathrm{T} 3$ vs. $\mathrm{T} 1$

RBC: GSH-Px activity $\uparrow$ by T2, T3, T7 vs. T1: SOD activity $\uparrow$ in $T 3$ vs. T1

Serum: MDA linear $\downarrow$; GSH linear $\uparrow$; GSH-Px, SOD and CAT activity quadratic $\uparrow$; all resveratrol vs. Cont. Bursa of Fabricius: HSP27 mRNA levels linear $\downarrow_{;}$HSP70 and HSP90 mRNA levels quadratic $\downarrow$; all resveratrol vs. Cont. 
Table 1 Effects of supplementary phytochemicals on oxidative status of poultry under cyclic chronic heat stress (CyCHS), constant chronic heat stress (CoCHS), and acute heat stress (AHS) (the birds were sampled at the end of HS, unless otherwise stated). Signicant effects on parameters of oxidative status are given for dietary treatments under HS conditions as compared to a heat stressed control (i.e. Cont. or T1). In case, both a non heat stressed (non supplemented) and heat stressed (non supplemented) control are included, data are used to confirm the presence of heat stress (Continued)

At 14 for $26 \mathrm{~d}$ all groups were exposed to $\mathrm{CyCHS}$ at $32+2^{\circ} \mathrm{C}$ for $8 \mathrm{~h} / \mathrm{d}$ followed by $19-24^{\circ} \mathrm{C}$

On d 21 after starting HS birds were sampled

At $\mathrm{d} 28$ for $14 \mathrm{~d}$ all groups were exposed to $\mathrm{CyCHS}$ at $34^{\circ} \mathrm{C}$ for $5 \mathrm{~h} / \mathrm{d}$ followed by $22^{\circ} \mathrm{C},(\mathrm{RH}=50-60 \%)$ On $\mathrm{d} 3$ and 14 after starting HS birds were sampled
Thymus: HSP27and HSP90 mRNA levels linear $\uparrow:$ HSP70 mRNA levels linear $\downarrow$; all resveratrol vs. Cont.

Spleen: HSP27, HSP70 and HSP90 mRNA levels quadratic all resveratrol vs. Cont.

Cobb 500 male broilers; dietary treatments starting at $\mathrm{d} 0$ of age 1. Cont., T1; 2. Cont. $+100 \mathrm{mg} / \mathrm{kg}$ vitamin E, T2; 3. Cont. + $7.5 \mathrm{mg} / \mathrm{kg}$ ginger root powder (GRP), T3; 4. Cont. $+15 \mathrm{mg} / \mathrm{kg}$ GRP, T4; 5. Cont. + 75 mg/kg ginger essential oil (GEO), T5; 6. Cont. $+150 \mathrm{mg} / \mathrm{kg} \mathrm{GEO}$, T6

Ross 308 broilers; dietary treatments starting at $d 25$ of age 1. Cont., T1; 2. Cont. + Curcuma xanthorrhiza essential oil (CXEO) at $200 \mathrm{mg} / \mathrm{kg}, \mathrm{T} 2 ; 3$. Cont. + CXEO at $400 \mathrm{mg} / \mathrm{kg}$, T3; 4. Cont. + Oreganum compactum essential oil (OCEO) at $200 \mathrm{mg} / \mathrm{kg}, \mathrm{T} 4$

5. Cont. + OCEO at $400 \mathrm{mg} / \mathrm{kg}$. 15
RBC. SOD activity $\downarrow$ by T5 + T6 vs. T1

Serum: Total antioxidant capacity $\uparrow$ by $T 2, T 3, T 4, T 5$, 6 vs. T1; MDA $\downarrow$ by $T 2, T 3, T 4, T 5, T 6$ vs. T1 Liver: SOD activity $\uparrow$ by $T 5+\mathrm{T} 6$ vs. T1; MDA $\downarrow$ by T3, T4, T5, T6 vs. T1

Plasma: MDA $\downarrow$ by $T 3$ vs. $T 1$ at $d 3 ; \downarrow$ by $T 2, T 3$, 4 vs. T1 at $d 14$

RBC: GSH content $\uparrow$ by T2, T3, T4, T5 vs. T1 at d 14 Liver: CAT activity $\uparrow$ by T2, T5 vs. T1 at $\mathrm{d} 14 \mathrm{~d}$

GSH-Px activity $\uparrow$ by T2 vs. T1 at d 14; SOD activity $\uparrow$ by T3 vs. T1 at $d$ 3; HSP70 mRNA levels $\downarrow$ by T5 vs. T1 at $d 3$ Kidney: SOD activity $\uparrow$ by T3, T5 vs. T1; SOD mRNA levels $\uparrow$ by T5 vs. T1; HSP70 mRNA levels $\downarrow$ by T5 vs. T1 at $d 3$ Heart: CAT activity $\uparrow$ by T3, T5 vs. T1; GSH-Px activity $\uparrow$ by $2, T 3, T 5$ vs levels $\uparrow$ by T3, T5 vs. T1; SOD mRNA levels $\uparrow$ by T3 vs. T1 all at $d$ 3; HSP70 mRNA levels $\downarrow$ by T3 vs. T1 at $d 14$

RH, relative humidity; MDA, malondialdehyde; GN, genistein; SC, Schisandra chinensis; LL, Ligustrum lucidum; GR, glutathione reductase; DPLM, dry powdered leaves of mint; RBC, red blood cell; GSH, glutathione; CAT, catalase; SOD, superoxide dismutase; FSE, Forsythia suspense extract; TAOC, total antioxidant capacity; BR, Brahma rassayana (made by the mixing extracts from plants); EGCG, epigallocatechin-3-gallate; $\mathrm{H}_{2} \mathrm{O}_{2}$, hydrogen peroxide; avUCP, avian uncoupling proteins; GSH-Px, glutathione peroxidase; EEP, ethanol extract of propolis; PTSCE, polyphenols extracted from Tamarindus indica seed coat; Nrf2, nuclear factor erythroid 2-related factor 2; GSSG, glutathione disulfide; BVE, Berberis vulgaris root extract; HO-1, haeme oxygenase-1; GST, glutathione-S-transferase; CNSK, cashew nut shell liquid; GSE, grape seed extract; ERW, electrolysed reduced water, CXEO, Curcuma xanthorrhiza essential oil; OCEO, Oreganum compactum essential oil; HSP, heat shock protein; LPE, lemon peel extract; OPE, orange peel extract; GRP, ginger root powder; GEO, ginger essential oil 
heat stressed laying hens [64]. The seeds of Schisandra chinensis contain lignans, while the seeds of Ligustrum lucidum contain oleanolic acid (a triterpenoid) amongst other principles. An extract from the dried fruits of Forsythia suspensa (another herb used in traditional Chinese medicine and containing the lignan pinoresinol) at $100 \mathrm{mg} / \mathrm{kg}$ showed a greater capacity than $200 \mathrm{mg} / \mathrm{kg}$ vitamin $\mathrm{C}$ in alleviating oxidative damage upon heat stress [65]. Further, Ramnath et al. [44] and Sujatha et al. [66] demonstrated that Brahma Rasayana extract and Stressroak, which are Ayurvedic polyherbal preparations, could relieve heat stress as compared to a control diet. Stressroak contains vitamin $\mathrm{C}$ and flavonoids as the active principles. The major Brahma Rasayana herbs are gooseberry (Emblica officinalis) and Indian gall nut (Terminalia chebula). In the study of Ramnath et al. [44], the preparation was fed starting $10 \mathrm{~d}$ prior to HS. Maini et al. [67] also tested a product containing fruits of $E$. officinalis, however, this time in a mixture with vitamin $\mathrm{E}$ and electrolytes. Its positive effects on red blood cells, heart, liver, and the brain cortex of constant chronic heat stressed broilers can thus not be ascribed solely to the presence of the herb. The same authors found also that dry powdered leaves of Mentha longifolia at 10, 20, and $30 \mathrm{~g} / \mathrm{kg}$ were beneficial. Seven et al. [38] supplemented diets of constant chronic heat stressed broilers with increasing amounts of an ethanol extract of propolis. In particular the higher dose $(3 \mathrm{~g} / \mathrm{kg})$ was able to ameliorate the oxidative status in different tissues similar to $250 \mathrm{mg} / \mathrm{kg}$ vitamin C. They identified 22 components in the extract; farnesol (a sesquiterpenoid) being the most abundant, followed by the flavone chrisin, 1-propen-1thiol, and 1-cyclohexene-1-methanol. Adding polyphenols extracted from Tamarindus indica seed coats did not provoke alleviation of oxidative damage upon increased temperatures [68]. Sahin and co-workers tested the efficacy of genistein (an isoflavone flavonoid; [43]), lycopene (a carotene with no vitamin A activity; [69]), epigallocatechin-3-gallate (a flavanol flavonoid; [29, 70]), tomato powder (containing $0.80 \mathrm{mg}$ lycopene, $0.13 \mathrm{mg} \beta$ carotene, $0.07 \mathrm{mg} \alpha$-tocopherol, $1.73 \mathrm{mg}$ vitamin $\mathrm{C}$ per $\mathrm{g}$ of powder; [71]), and Berberis vulgaris root extract (chemical composition given in [72]), in cyclic heat stress models with Japanese quails. They found beneficial effects, and for some phytochemicals they gave evidence that this was achieved by activating the host defense system at the cellular level, substantiated by up-regulation of the transcription factor Nrf2 and down-regulation of NF- $\mathrm{KB}$ [29, 71, 72]. Sahin et al. [71] demonstrated high and significant correlations between feed intake and egg production on the one hand and Nrf2 (positive) and NF-kB (negative) on the other, irrespective of epigallocatechin-3gallate supplementation addressing their role in mediating oxidative stress responses. Sahin et al. [73] reviewed possible molecular targets of dietary phytochemicals for the alleviation of heat stress in poultry. In concreto, the cell signaling modulating effects of epigallocatechin-3-gallate, lycopene, resveratrol, and curcumin are discussed. Sahin et al. [69] demonstrated that by supplementing lycopene, its serum concentration increased dose-dependently. The positive effects of resveratrol (a stillbenoid) were shown by Liu et al. [74] in a dose-response study. Resveratrol attenuated the heat stress induced over expression of HSP27, HSP70, and HSP90 mRNA in the bursa of Fabricius and spleen, and increased the low expression of HSP27 and HSP90 mRNA in the thymus upon heat stress. It also showed positive effects on oxidative status parameters in serum. The heat-shock response, through activation of heat-shock transcription factors and the elevated expression of inducible HSP and molecular chaperones, protects the cell against the accumulation of non-native proteins. HSPs interact with those proteins to hold them together properly and retain their functionality, hence exhibiting a major contribution to cell integrity under these stress conditions. Proper expression of HSP is fundamental to the protective heat stress response. Azad et al. [47] showed clearly that electrolyzed reduced water (not a phytochemical, but mentioned here for comparison) could alleviate the negative effects of HS on feed consumption and body weight gain, while it had no significant effects on MDA and $\mathrm{H}_{2} \mathrm{O}_{2}$ formation in muscles. Electrolyzed reduced water was provided to the chickens as a source of "active hydrogen" which is believed to act as a ROS scavenger without producing oxidized molecules after reduction. Conversely, grape seed extract [rich in proanthocyanidins (oligomers of the flavanols catechin and epicatechin) vitamin $\mathrm{E}$, and other flavonoids] significantly reduced $\mathrm{H}_{2} \mathrm{O}_{2}$ production in muscles, whereas no effect was seen on performance. Habibi et al. [75] worked with ginger root powder ( 7.5 and $15 \mathrm{mg} / \mathrm{kg}$ ) and a hydro distillate thereof (essential oil; 75 and $150 \mathrm{mg} / \mathrm{kg}$ ); the latter having 12 constituents identified, with zingiberene, $\beta$ sesquiphellandrene, sabinene, ar-curcumene, and $\beta$ bisabolene as major components; all being sesquiterpenes except sabinine which is a monoterpene. All treatments, including the positive control vitamin E $(100 \mathrm{mg} / \mathrm{kg})$ improved serum oxidative status, but only the ginger oil increased SOD activity in the liver and both ginger root and oil reduced liver MDA as compared to controls. Recently, our studies have shown that phenolic compounds produce beneficial effects on poultry owing to their antioxidant, anti-inflammatory, and antimicrobial activities [76, 77]. Moreover, in other work from our group [78, 79], we have shown that Curcuma xanthorrhiza essential oil, Oreganum compactum essential oil, and orange peel extract are able to improve the oxidative status of broiler chickens under cyclic chronic HS (28-day-old Ross 308 broilers were exposed to $34{ }^{\circ} \mathrm{C}$ for $5 \mathrm{~h} / \mathrm{d}$ followed by $22^{\circ} \mathrm{C}$ for $14 \mathrm{~d}$ ). Curcuma xanthorrhiza essential oil is characterized by arcurcumene (11.4\%), $\beta$-curcumene (8.5\%; sesquiterpenes), 
and xanthorrizhol (28\%, a sesquiterpenoid) and in both studies showed significant improvements in the oxidative status of various tissues, mainly at the higher inclusion of $400 \mathrm{mg} / \mathrm{kg}$. Oreganum compactum essential oil, containing the monoterpenoids carvacrol (44.9\%) and thymol (16.4\%) showed inferior improvements almost exclusively at the higher dose $(400 \mathrm{mg} / \mathrm{kg})$. The significant effects of orange peel extract were limited to increasing erythrocyte GSH-Px activity for the $400 \mathrm{mg} / \mathrm{kg}$ treatment, likely because of the low content of active principles in the extract.

It appears to be difficult to identify a consistent pattern of functional antioxidant phytochemicals. Nevertheless, several studies found positive results with terpenes/terpenoids, and in particular with sesquiterpenes/sesquiterpenoids (ethanol extract of propolis, Curcuma xanthorrhiza essential oil, and ginger root oil). Lignans in traditional Chinese medicine herbs and lycopene have also showed positive results. Nonetheless, in the majority of the studies the beneficial principles were various types of flavonoids and related compounds (proanthocyanidins and resveratrol), either in combination or not with vitamin C or E. Surai [79] questioned the in vivo direct antioxidant effects of flavonoids, basically because these compounds are poorly absorbed in the gut, rapidly metabolized and excreted resulting in physiologically low concentrations in target tissues (e.g. mostly lower than $1 \mu \mathrm{mol} / \mathrm{L}$ in the plasma of healthy subjects). In none of the studies using flavonoids from Table 1 were the tissue concentrations of the active principle measured. In most studies shown in Table 1 it was reported that these phytochemicals were beneficial to heat stressed poultry but were less or ineffective in non-heat-stressed poultry (e.g. [43, 70, 71]; this supports the contention that antioxidant phytochemicals might have potential in challenging conditions. None of the beneficial effects of these phytochemicals were confirmed in a second study, except for those associated with epigallocathechin-3-gallate and Curcuma xanthorrhiza essential oil, which were tested twice by the same research groups $([29,70]$ and $[78,79]$; respectively). Therefore, we suggest that more studies are needed in this subject; in particular, well-designed dose-response studies (dose effect is poorly addressed in the above studies) including non-heat stressed control treatments that investigate the mode of action are warranted.

\section{Conclusions}

Current evidence strongly suggests that HS induces oxidative stress in poultry. The current review focused on mitochondrial dysfunction upon heat stress. It is suggested that mitigation of mitochondrial dysfunction can be approached though various nutritional strategies: 1 ) reduction of the membrane potential (e.g. mild uncoupling), 2) improvement of ETC. efficiency, or 3) enforcement of the host's capacity to detoxify ROS. Currently, only evidence with regard to the latter strategy is available. Several studies found positive results with terpenes/terpenoids, and in particular with sesquiterpenes/sesquiterpenoids (ethanol extract of propolis, Curcuma xanthorrhiza essential oil, and ginger root oil). Lignans in traditional Chinese medicinal herbs and lycopene showed positive results. Nonetheless, in the majority of studies, the beneficial principles were various types of flavonoids and related compounds (proanthocyanidins and resveratrol), either in, or not in combination with vitamin $\mathrm{C}$ or E. Epigallocatechin3-gallate and lycopene were found to interact with cell signaling pathways. It was repeatedly reported that these phytochemicals were beneficial to heat stressed poultry but were less or not effective in non-heat-stressed control birds. This supports the contention that antioxidant phytochemicals might have potential in challenging conditions.

\section{Additional files}

Additional file 1: Table S1. Effects of acute heat stress (HS) on oxidative status of poultry (the birds were sampled at the end of HS, unless otherwise stated). Cont. refers to non heat stressed birds. (DOCX $41 \mathrm{~kb}$ )

Additional file 2: Table S2. Effects of cyclic chronic heat stress (CyCHS) and constant chronic heat stress (CoCHS) on oxidative status of poultry (the birds were sampled at the end of HS, unless otherwise stated). Cont refers to non heat stressed birds. (DOCX $44 \mathrm{~kb}$ )

\begin{abstract}
Abbreviations
2-Cys PRX, 2-Cys peroxiredoxin; 3HADH, 3-hydroxyacyl CoA dehydrogenase; ANT, adenine nucleotide translocator; AP-1, activator protein 1; ARE, antioxidant response element; avUCP, avian uncoupling protein; $\mathrm{CCO}$, cytochrome $\mathrm{C}$ oxidase; CNSL, cashew nut shell liquid; CS, citrate synthase; ETC, electron transport chain; FADH2, flavin adenine dinucleotide; GSH, reduced glutathione; GSH-Px, glutathione peroxidase; GSSG, glutathione disulfide; HS, heat stress; HSP, heat-shock proteins; MDA, malondialdehyde; NCCR, nicotinamide adenine dinucleotide cytochrome c reductase; NF-kB, nuclear factor kappa-light-chain-enhancer of activated B; Nrf2, nuclear factor (erythroid-derived 2)-like 2; OS, oxidative stress; ROS, reactive oxygen species; RS, reactive species; SCCR, succinate cytochrome c reductase; SOD, superoxide dismutase; TCA, tricarboxylic acid cycle; UCP, Uncoupling proteins
\end{abstract}

\section{Funding}

Thanks are due to the Special Research Fund (BOF) of Ghent University (Belgium) for the financial support of Abdollah Akbarian (grant number 01SF2711).

\section{Authors' contributions}

All authors have read and approved the final manuscript and take full responsibility for the final content. AA and JM have searched primary sources, compiled available data and written the manuscript. JD, MM, AG and SDS have revised the manuscript. AA and JM edited the manuscript. All authors read and approved the final manuscript.

\section{Competing interests}

The authors declare no conflicts of interest.

\section{Author details}

${ }^{1}$ Department of Animal Production, Laboratory for Animal Nutrition and Animal Product Quality, Ghent University, Proefhoevestraat 10, Melle 9090, Belgium. ${ }^{2}$ Centre of Excellence in the Animal Science Department, Ferdowsi University of Mashhad, P.O. Box: 91775-1163, Mashhad, Iran. ${ }^{3}$ Department of Applied Biosciences, Ghent University, Valentin Vaerwyckweg 1, Ghent 9000, Belgium. 
Received: 3 January 2016 Accepted: 15 June 2016 Published online: 28 June 2016

\section{References}

1. Lara LJ, Rostagno MH. Impact of heat stress on poultry production. Animals. 2013;3:356-69

2. Yahav S. Alleviating heat stress in domestic fowl: different strategies. World's Poult Sci J. 2009;65:719-32.

3. Syafwan S, Kwakkel RP, Verstegen MWA. Heat stress and feeding strategies in meat-type chickens. World's Poult Sci J. 2011;67:653-73.

4. Renaudeau D, Collin A, Yahav S, De Basilio V, Gourdine JL, Collier RJ. Adaptation to hot climate and strategies to alleviate heat stress in livestock production. Anim. 2012;6:707-28.

5. Lin H, Jiao HC, Buyse J, Decuypere E. Strategies for preventing heat stress in poultry. World's Poult Sci J. 2006;62:71-86.

6. Loyau T, Bedrani L, Berri C, Métayer-Coustard S, Praud C, Coustham V, et al. Cyclic variations in incubation conditions induce adaptive responses to later heat exposure in chickens: a review. Anim. 2015;9:76-85.

7. Altan Ö, Pabuccuoglu A, Altan A, Konyalioglu S, Bayraktar $\mathrm{H}$. Effect of heat stress on oxidative stress, lipid peroxidation and some stress parameters in broilers. Brit Poult Sci. 2003:44:545-50

8. Sahin K, Onderci M, Sahin N, Gursu MF, Kucuk O. Dietary vitamin C and folic acid supplementation ameliorates the detrimental effects of heat stress in Japanese quail. J Nutr. 2003;133:1882-6.

9. Mujahid A, Yoshiki Y, Akiba Y, Toyomizu M. Superoxide radical production in chicken skeletal muscle induced by acute heat stress. Poult Sci. 2005;84:307-14.

10. Lin H, Decuypere E, Buyse J. Acute heat stress induces oxidative stress in broiler chickens. Comp Biochem Physiol Part A: Mol \& Integr Physiol. 2006; 144:11-7.

11. Halliwell $B$, Whiteman M. Measuring reactive species and oxidative damage in vivo and in cell culture: how should you do it and what do the results mean? Brit J Pharmacol. 2004;142:231-55.

12. Davies JA. Oxidative stress: the paradox of aerobic life. Free Rad Oxid Stress: Environ Drugs Food Add. 1995;61:1-13.

13. Hansfort RG, Hogue BA, Mildaziene V. Dependence of $\mathrm{H}_{2} \mathrm{O}_{2}$ formation by rat heart mitochondria on substrate availability and donor age. J Bioenergetics Biomembranes. 1997:29:89-95.

14. Pamplona R, Costantini D. Molecular and structural antioxidant defenses against oxidative stress in animals. Am J Physiol-Reg Integr Comp Physiol. 2011;301:R843-63

15. Wood ZA, Poole LB, Karplus PA. Peroxiredoxin evolution and the regulation of hydrogen peroxide signaling. Science. 2003;300:650-3.

16. Yang $L$, Tan GY, Fu YQ, Feng $J H$, Zhang MH. Effects of acute heat stress and subsequent stress removal on function of hepatic mitochondrial respiration, ROS production and lipid peroxidation in broiler chickens. Comp Biochem Physiol Part C: Tox \& Pharmacol. 2010;151:204-8.

17. Mujahid A, Akiba Y, Warden CH, Toyomizu M. Sequential changes in superoxide production, anion carriers and substrate oxidation in skeletal muscle mitochondria of heat-stressed chickens. FEBS Lett. 2007;581: $3461-7$

18. Green K, Brand MD, Murphey MP. Prevention of mitochondrial oxidative damage as a therapeutic strategy in diabetes. Diabetes. 2004;53:5110-8.

19. Kikusato M, Toyomizu M. Crucial role of membrane potential in heat stressinduced overproduction of reactive oxygen species in avian skeletal muscle mitochondria. PLoS One. 2013;8:e64412.

20. Kikusato M, Ramsey AJJ, Amo T, Toyomizu M. Application of modular kinetic analysis to mitochondrial oxidative phosphorylation in skeletal muscle of birds exposed to acute heat stress. Febs Lett. 2010:584:3143-8.

21. Mujahid A, Akiba Y, Toyomizu M. Olive oil-supplemented diet alleviates acute heat stress-induced mitochondrial ROS production in chicken skeletal muscle. Am J Physiol-Reg Integr Comp Physiol. 2009:290:690-8.

22. Mujahid A, Sato K, Akiba Y, Toyomizu M. Acute heat stress stimulates mitochondrial superoxide production in broiler sleletal muscle, possibly via downregulation of uncoupling protein content. Poult Sci. 2006;85: 1259-65.

23. Del Vesco AP, Gasparino E. Production of reactive oxygen species, gene expression, and enzymatic activity in quail subjected to acute heat stress. J Anim Sci. 2013:91:582-7.

24. Tan GY, Yang L, Fu YQ, Feng JH, Zhang MH. Effects of different acute high ambient temperatures on function of hepatic mitochondrial respiration, antioxidative enzymes, and oxidative injury in broiler chickens. Poult Sci. 2010;89:115-22.

25. Azad MAK, Kikusato M, Sudo S, Amo T, Toyomizu M. Time course of ROS production in skeletal muscle mitochondria from chronic heat-exposed broiler chicken. Comp Biochem Physiol Part A: Mol Integr Physiol. 2010; 157:266-71.

26. Echtay KS, Esteves TC, Pakay JL, Jekabsons MB, Lambert AJ, Portero-Otin $\mathrm{M}$, et al. A signalling role for 4-hydroxy-2-nonenal in regulation of mitochondrial uncoupling. EMBO J. 2003;22:4103-10.

27. Mujahid A, Pumford NR, Bottje W, Nakagawa K, Miyazawa T, Akiba Y, Toyomizu M. Mitochondrial oxidative damage in chicken skeletal muscle induced by acute heat stress. J Poult Sci. 2007:44:439-45.

28. Leonarduzzi G, Sottero B, Poli G. Targeting tissue oxidative damage by means of cell signaling modulators: The antioxidant concept revisited. Pharmacol Therapeutics. 2010;128:336-74.

29. Sahin K, Orhan C, Tuzcu M, Ali S, Sahin N, Hayirli A. Epigallocatechin-3 gallate prevents lipid peroxidation and enhances antioxidant defence system via modulating hepatic nuclear transcription factors in heat-stressed quails. Poult Sci. 2010;89:2251-8.

30. Orhan C, Tuzcu M, Gencoglu H, Sahin N, Hayirli A, Sahin K. Epigallocatechin-3gallate exerts protective effects against heat stress through modulating stressresponsive transcription factors in poultry. Brit Poult Sci. 2013;54:447-53.

31. Montilla SIR, Johnson TP, Pearce SC, Gardan-Salmon D, Gabler NK, Ross JW, et al. Heat stress causes oxidative stress but not inflammatory signaling in porcine skeletal muscle. Temperature. 2014;1:42-50.

32. Yu JM, Bao ED, Yan JY, Lei L. Expression and localization of Hsps in the heart and blood vessel of heat-stressed broilers. Cell Stress Chaperones. 2008:13:327-35

33. Gu XH, Hao Y, Wang XL. Overexpression of heat shock protein 70 and its relationship to intestine under acute heat stress in broilers: 2 . Intestinal oxidative stress. Poult Sci. 2012;91:790-9.

34. Barrett MJ, Alones V, Wang KX, Phan L, Swerdlow RH. Mitochondria-derived oxidative stress induces a heat shock protein response. J Neurosci Res. 2004 78:420-9.

35. Wang RR, Pan XJ, Peng ZQ. Effects of heat exposure on muscle oxidation and protein functionalities of pectoralis major in broilers. Poult Sci. 2009;88: 1078-84.

36. Toyomizu M, Azad MAK, Kikusato M, Maekawa T, Shirakawa. Metabolic characteristics and oxidative damage to skeletal muscle in broiler chickens exposed to chronic heat stress. Comp Biochem Physiol Part A: Mol Integr Physiol. 2010;155:401-6.

37. Pamok S, Aengwanich W, Komutrin T. Adaptation to oxidative stress and impact of chronic oxidative stress on immunity in heat-stressed broilers. J Thermal Biol. 2009;34:353-7.

38. Seven PT, Yilmaz S, Seven I, Cerci IH, Azman MA, Yilmaz M. Effects of propolis on selected blood indicators and antioxidant enzyme activities in broilers under heat stress. Acta Veterinario Brno. 2009:78:75-83.

39. Dridi S, Temim S, Derouet M, Tesseraud S, Taouis M. Acute cold- and chronic heat-exposure upregulate hepatic leptin and muscle uncoupling protein (UCP) gene expression in broiler chickens. J Exp Zoology Part A-Ecol Gen Physiol. 2008:309A:381-8.

40. Sahin N, Onderci M, Sahin K, Gursu MF, Smith MO. Ascorbic acid and melatonin reduce heat-induced performance inhibition and oxidative stress in Japanese quails. Brit Poult Sci. 2004;45:116-22.

41. Gursu MF, Onderci M, Gulcu F, Sahin K. Effects of vitamin C and folic acid supplementation on serum paraoxonase activity and metabolites induced by heat stress in vivo. Nutr Res. 2004;24:157-64.

42. Sohail MU, Rahman ZU, ljaz A, Yousaf MS, Yagub T, Zaneb H, et al. Single or combined effects of mannan-oligosaccharides and probiotic supplements on the total oxidants, total antioxidants, enzymatic antioxidants, liver enzymes, and serum trace minerals in cyclic heatstressed broilers. Poult Sci. 2011:90:2573-7.

43. Onderci M, Sahin K, Sahin N, Gursu MF, Doerge D, Sarkar FH, et al. The effect of genistein supplementation on performance and antioxidant status of Japanese quail under heat stress. Arch Anim Nutr. 2004;58:463-71.

44. Ramnath A, Rekha PS, Sujatha S. Amelioration of heat stress induced disturbances of antioxidant defense system in chicken by Brahma Rasayana. Evid Based Compl Alt. 2008:5:77-84.

45. Willemsen H, Swennen Q, Everaet N, Geraert P-A, Mercier Y, Stinckens A, et al. Effects of dietary supplementation of methionine and its hydroxyl analog DL-2-hydroxy-4-methylthiobutanoic acid on growth performance, plasma 
hormone levels, and the redox status of broiler chickens exposed to high temperature. Poult Sci. 2011:90:2311-20.

46. Michiels J, Tagliabue MM, Akbarian A, Ovyn A, De Smet S. Oxidative status and meat quality of broiler chickens reared under free-range and feedrestricted conditions as compared to conventional indoors. Avian Biol Res. 2014;7:74-82.

47. Azad MKA, Kikusato M, Zulkifi I, Toyomizu M. Electrolysed reduced water decreases reactive oxygen species-induced oxidative damage to skeletal muscle and improves performance in broiler chickens exposed to mediumterm chronic heat stress. Brit Poult Sci. 2013;54:503-9.

48. Toyomizu M, Okamoto K, Ishibashi T, Chen ZQ, Nakatsu T. Uncoupling effect of anacardic acids from cashew nut shell oil on oxidative phosphorylation of rat liver mitochondria. Life Sci. 2000;66:229-34.

49. Geng AL, Guo YM, Yuan JM. Effects of dietary L-carnitine and coenzyme $\mathrm{Q}(10)$ supplementation on performance and ascites mortality of broilers Arch Anim Nutr. 2004;58:473-82.

50. Cawthon D, McNew R, Beers KW, Bottje WG. Evidence of mitochondrial dysfunction in broilers with pulmonary hypertension syndrome (ascites): Effect of t-butyl hydroperoxide on hepatic mitochondrial function, glutathione, and related thiols. Poult Sci. 1999;78:114-24.

51. Tang Z, labal M, Cawthon D, Bottje WG. Heart and breast muscle mitochondria dysfunction in pulmonary hypertension syndrome in broilers (Gallus domesticus). Comp Biochem Physiol a-Mol Integr Physiol. 2002;132:527-40.

52. Huang $B Y$, Guo YM, Hu XF, Song Y. Effects of coenzyme Q(10) on growth performance and heart mitochondrial function of broilers under high altitude induced hypoxia. J Poult Sci. 2011;48:40-6.

53. Arslan C. L-carnitine and its use as a feed additive in poultry feeding a review. Revue Med Vet. 2006;157:134-42.

54. Jia R, Bao YH, Zhang Y, Ji C, Zhao LH, Zhang JY, Gao CQ, et al. Effects of dietary alpha-lipoic acid, acetyl-L-carnitine, and sex on antioxidative ability, energy, and lipid metabolism in broilers. Poult Sci. 2013;93:2809-17.

55. Wang YW, Ning D, Peng YZ, Guo YM. Effects of Dietary L-carnitine supplementation on growth performance, organ weight, Biochemical parameters and ascites susceptibility in broilers reared under lowtemperature environment. Asian-Austr J Anim Sci. 2013;26:233-40.

56. Yousefi A, Khajali F, Hassanpour H, Khajali Z. Dietary L-carnitine improves pulmonary hypertensive response in broiler chickens subjected to hypobaric hypoxia. J Poult Sci. 2013:50:143-9.

57. Packer L, Valenza M, Serbinosa E, Starke-Reed P, Frost K, Kagan V. Free radical scavenging is involved in the protective effects of $\mathrm{L}$-propionyl-carnitine against ischemia reperfusion injury of the heart. Arch Biochem Biophys. 1991;288:533-7.

58. Del Vesco AP, Gasparino E, Grieser DO, Zancanela V, Gasparin FRS, Constantin J, et al. Effects of methionine supplementation on the redox state of acute heat stress-exposed quails. J Anim Sci. 2014;92:806-815.

59. Surai PF. Selenium in poultry nutrition - 1. Antioxidant properties, deficiency and toxicity. World's Poult Sci J. 2002;58:333-47.

60. Khan RU, Naz S, Nikousefat Z, Selvaggi M, Laudadio V, Tufarelli V. Effect of ascorbic acid in heat-stressed poultry. World's Poult Sci J. 2012;68:477-89.

61. Khan RU, Naz S, Nikousefat Z, Tufarelli V, Javdani M, Rana N, et al. Effect of vitamin $E$ in heat-stressed poultry. World's Poult Sci J. 2011;67:469-77.

62. Mujahid A. Nutritional strategies to maintain efficiency and production of chickens under high environmental temperature. J Poult Sci. 2011;48:145-54.

63. Ma DY, Shan AS, Chen ZH, Du J, Song K, Li JP, et al. Effect of Ligustrum lucidum and Schisandra chinensis on the egg production, antioxidant status and immunity of laying hens during heat stress. Arch Anim Nutr. 2005;59:439-47.

64. Wang L, Piao XL, Kim SW, Piao XS, Shen YB, Lee HS. Effects of Forsythia suspense extract on growth performance, nutrient digestibility, and antioxidant activities in broiler chickens under high ambient temperature. Poult Sci. 2008:87:1287-94.

65. Sujatha V, Korde JP, Rastogi SK, Maini S, Ravikanth K, Rekhe DS. Amelioration of heat stress induced disturbances of the antioxidant defence system in broilers. J Vet Med Anim Health. 2010;2(3):18-28.

66. Maini S, Rastogi SK, Korde JP, Madan AK, Shukla SK. Evaluation of oxidative stress and its amelioration through certain antioxidants in broilers during summer. J Poult Sci. 2007:44:339-47.

67. Aengwanich W, Suttajit M. Effect of polyphenols extracted from tamarind (Tamarinus indica L.) seed coat on physiological changes, heterophil/ lymphocyte ratio, oxidative stress and body weight of broilers (Gallus domesticus) under chronic heat stress. Anim Sci J. 2010;81:264-70.
68. Sahin K, Onderci M, Sahin N, Gursu MF, Khachik F, Kucuk O. Effects of lycopene supplementation on antioxidant status, oxidative stress, performance and carcass charecteristics in heat-stressed Japanese quail. J Therm Biol. 2006;31:307-12.

69. Tuzcu M, Sahin N, Karatepe M, Cikim G, Kilinc U, Sahin K. Epigallocatechin-3gallate supplementation can improve antioxidant status in stressed quail. Brit Poult Sci. 2006:49:643-8.

70. Sahin K, Orhan C, Akdemir F, Tuzcu M, Ali S, Sahin N. Tomato powder supplementation activates Nrf-2 via ERK/Akt signaling pathway and attenuates heat stress-related responses in quails. Anim Feed Sci Technol. 2011;165:230-7.

71. Sahin K, Orhan C, Tuzcu M, Borawska MH, Jablonski J, Guler O, et al. Berberis vulgaris root extract alleviates the adverse effects of heat stress via modulating hepatic nuclear transcription factors in quails. Brit I Nutr. 2013;111:609-16.

72. Sahin K, Orhan C, Smith MO, Sahin N. Molecular targets of dietany phytochemicals for the alleviation of heat stress in poultry. World's Poult Sci J. 2013;69:113-23.

73. Liu LL, He JH, Xie HB, Yang YS, Li JC, Zou Y. Resveratrol induces antioxidant and heat shock protein mRNA expression in response to heat stress in black-boned chickens. Poult Sci. 2014;93:54-62.

74. Habibi R, Sadeghi G, Karimi A. Effect of different concentrations of ginger root powder and its essential oil on growth performance, serum metabolites and antioxidant status in broiler chicks under heat stress. Brit Poult Sci. 2014;55:228-37.

75. Akbarian A, Golian A, Gilani A, Kermanshahi H, Zhaleh S, Akhavan A, et al. Effect of feeding citrus peel extracts on growth performance, serum components, and intestinal morphology of broilers exposed to high ambient temperature during the finisher phase. Livest Sci. 2013;157:490-7.

76. Akbarian A, Golian A, Kermanshahi H, Farhoosh R, Raji AR, De Smet S, et al. Growth performance and gut health parameters of finishing broilers supplemented with plant extracts and exposed to daily increased temperature. Span J Agri Res. 2013;11:109-19.

77. Akbarian A, Michiels J, Golian A, Buyse J, Wang Y, De Smet S. Gene expression of heat shock protein 70 and antioxidant enzymes, oxidative status, and meat oxidative stability of cyclically heat-challenged finishing broilers fed Origanum compactum and Curcuma xanthorrhiza essential oils. Poult Sci. 2014;93:1930-41.

78. Akbarian A, Golian A, Kermanshahi H, De S, Michiels J. Antioxidant enzyme activities, plasma hormone levels and serum metabolites of finishing broiler chickens reared under high ambient temperature and fed lemon and orange peel extracts and Curcuma xanthorrhiza essential oil. J Anim Physiol Anim Nutr. 2015:99:150-62.

79. Surai PF. Polyphenol compounds in the chicken/animal diet: from the past to the future. J Anim Physiol Anim Nutr. 2013;98:19-31.

\section{Submit your next manuscript to BioMed Central and we will help you at every step:}

- We accept pre-submission inquiries

- Our selector tool helps you to find the most relevant journal

- We provide round the clock customer support

- Convenient online submission

- Thorough peer review

- Inclusion in PubMed and all major indexing services

- Maximum visibility for your research

Submit your manuscript at www.biomedcentral.com/submit 